\title{
Del malestar a la depresión: dinámicas en la construcción del significado personal de la experiencia de la depresión
}

\section{From Discomfort to Depression: Dynamics in Building Personal Meaning from the Depressive Experience}

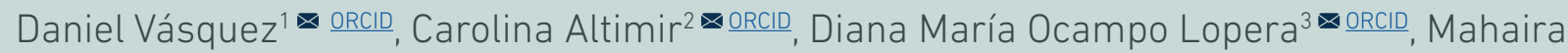

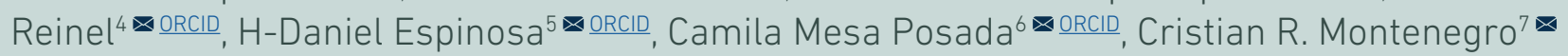
$\underline{\mathrm{ORCID}}$, Olga María Fernández González $z^{8} \underline{\mathrm{ORCID}}$, Mariane Krause $^{9 \mathrm{ORCID}}$

124589 Instituto Milenio para la Investigación de la Depresión y la Personalidad (MIDAP)

${ }^{2}$ Universidad Alberto Hurtado

2479 Pontificia Universidad Católica de Chile

${ }^{8}$ Universidad de Chile

Chile

${ }^{356}$ Universidad CES

Colombia

Fecha correspondencia:

Recibido: diciembre 9 de 2019.

Aceptado: octubre 2 de 2020.

Forma de citar:

Vásquez, D., Altimir, C. Ocampo

Lopera, D.M. Reinel Pineda,

M., Espinosa, H-D., Mesa, C.,

Montenegro, C.R., Fernández

González, O.M. \& Krause, M. (2020).

Del malestar a la depresión:

dinámicas en la construcción

del significado personal de la

experiencia de la depresión. Rev.

CES Psico, 13(3), 142-161.

Open access

(c) Copyright

Licencia creative commons

Comparte

\section{Resumen}

Objetivo: Comprender las dinámicas mediante las cuales los pacientes significan su experiencia de la depresión. Metodología: Se utilizó una metodología cualitativa, basada en la Teoría Fundamentada. Se realizaron entrevistas semiestructuradas a 10 pacientes diagnosticados de un trastorno del ánimo con episodio depresivo, por el que habían estado en tratamiento psicoterapéutico previamente. Las entrevistas fueron analizadas desde un enfoque descriptivo-relacional, para reconocer las principales unidades temáticas referidas por los participantes y luego identificar sus relaciones y significados subyacentes. Resultados: El significado de la experiencia de la depresión se reveló como un proceso denominado "Construcción subjetiva de la experiencia de la depresión", caracterizado por tres momentos. (1) "La experiencia de un malestar sin nombre"; (2) "Anclaje de la experiencia del paciente en la palabra depresión"; (3) "Apropiación de la experiencia de la depresión". Conclusión: la experiencia de la depresión se presenta como un proceso dinámico de interacción entre el malestar subjetivo y la construcción de significados asociados a él; transitando de una experiencia desconcertante observada en el cuerpo, el ánimo y/o lo conductual, hacia una experiencia elaborable discursivamente, a través de una referencia semántica (depresión) que integra los significados y origina un proceso de apropiación de lo que implica para cada individuo tener depresión o estar deprimido.

Palabras clave: Depresión, Enfermedad Mental, Metodología Cualitativa, Psicoterapia, Experiencia, Subjetiva. 
Ética de publicaciones

Revisión por pares

Gestión por Open Journal

System

DOl: http://dx.doi. org/10.21615/cesp.13.3.9

ISSN: 2011-3080

\section{Sobre los autores:}

1. Psicólogo. Instituto Milenio para la Investigación en Depresión y Personalidad

2. Doctora en Psicoterapia. Investigadora Adjunta Instituto Milenio para la Investigación en Depresión y Personalidad (MIDAP), Académica, Facultad de Psicología, Universidad Alberto Hurtado, Profesora Asistente Adjunta Pontificia Universidad Católica de Chile. Directora de Psicoterapia y Cambio - Red Latinoamericana de Investigación en Psicoterapia, Subdirectora Centro de Investigación en Psicoterapia (CIPsi).

3. Magister. Docente Investigadora Universidad CES. Coordinadora Centro de Atención en Salud, Universidad CES.

4. Estudiante Doctorado en Psicoterapia, Instituto Milenio para la Investigación en Depresión y Personalidad. MIDAP.

5. Doctor en Psicoterapia. Docente Investigador Universidad CES. Instituto Milenio para la Investigación en Depresión y Personalidad, MIDAP.

6. Psicóloga. Psicóloga clínica en Centro de Atención en Salud, Universidad CES.

\section{Abstract}

Objective: To understand the dynamics by which patients signify their depressive experience. Methodology: A qualitative methodology was used, based on the Grounded Theory. Semi-structured interviews were conducted with 10 patients diagnosed with a mood disorder with depressive episode, who had been in a psychotherapy treatment about it. The interviews were analyzed from a descriptive-relational approach, recognizing the main thematic units referred by the participants, and then identifying their relationships and underlying meanings. Results: The meaning of "depression" experience was revealed as a process, named "subjective construction of depression experience", characterized by three moments: (1) "The experience of an unnamed discomfort"; (2) "Anchoring the patient's experience in the word depression"; (3) "Appropriation of depression experience". Conclusion: The depressive experience is presented as a dynamic process of interaction between subjective discomfort and the construction of meanings associated to it. Transitioning from a disconcerting experience observed on their body, mood, and/or their behaviour, to something available to be elaborated discursively, through a semantic reference (depression) that integrates them, originates a process of appropriation about what it implies for each individual to be depressed or have depression.

Keywords: Depression, Mental Illness, Qualitative Methodology, Psychotherapy, Experience, Subjective.

\section{Introducción}

De acuerdo con la Organización Mundial de la Salud (2020), la depresión afecta a más de 300 millones de personas. En Chile, un 6,2\% de la población sufre de esta enfermedad (Subsecretaria de Salud Pública, 2017), y los mayores porcentajes de depresión se encuentran en las mujeres (25,7\%), en la población con edad para trabajar (25 a 64 años) y en grupos de menores ingresos (Centro de Estudios de Conflicto y Cohesión Social [COES], 2018). En Colombia, por su parte, un 5,4\% de la población ha sufrido de depresión en los últimos 12 meses (Ministerio de Salud y Protección Social y Colciencias, 2015), siendo los adolescentes quienes presentan la mayor prevalencia (15,8\%), seguido del grupo de personas de 45 años y más (8,9\%). La relevancia social de este problema es doble, por una parte, está ligada etiológicamente a condiciones contextuales de tipo social y cultural, tales como el deterioro de los vínculos comunitarios y del apoyo social (Krause et al., 2015); por otra, este trastorno altera negativamente la vida de las personas que lo padecen, así como el entorno familiar y social, generando significativas pérdidas económicas a la sociedad (Sobocki, Jönsson, Angst, \& Rehnberg, 2006).

La evidencia empírica sobre esta enfermedad señala que es un trastorno complejo, multideterminado y clínicamente heterogéneo, cuyas manifestaciones psicopatológicas se relacionan con la manera como interactúan factores de personalidad, biológicos y ambientales a lo largo del ciclo vital (Botto, Acuña, \& Jiménez, 2014; Holtzheimer, \& Mayberg, 2011; Luyten, Blatt, \& Corveleyn, 2005). A su vez, demuestra que tanto el grado de severidad como la manifestación de la depresión varían de acuerdo con los contextos sociales y culturales (Villaseñor, Rojas, Albarrán, \& Gonzáles, 2006), lo que subraya la relevancia que estos factores tienen en la experiencia de la depresión (Kleinman, 1995). Esta complejidad de la depresión incide sobre las respuestas diferenciales de los pacientes a los tratamientos recibidos (Corveleyn, Luyten, \& Blatt, 2005). 
7. PhD. Social Research Methods. Sociólogo. Profesor e Investigador, Escuela de Enfermería, Pontificia Universidad Católica de Chile. Investigador Joven, Instituto Milenio para la Investigación en Depresión y Personalidad, MIDAP. Cofundador, Platform for Social Research on Mental Health in Latin America (PLASMA).

8. Doctora en Psicoterapia. Investigadora Adjunta Instituto Milenio para la Investigación de la Depresión y la Personalidad (MIDAP).

9. PhD. en Psicología de la Universidad Libre de Berlín. Profesora Titular de la Pontificia Universidad Católica de Chile. Investigadora Asociada Instituto Milenio para la Investigación en Depresión y Personalidad, MIDAP. Presidenta Consejo CONICYT.

\section{El estudio de la depresión desde la subjetividad}

El estudio de la subjetividad busca rescatar los significados que la "realidad" tiene para los actores sociales involucrados con la finalidad de realizar una interpretación de segundo orden (Berger \& Luckmann, 1968), es decir, construir desde la investigación un modelo de los significados del otro. Lo desafiante de esta aproximación es entender, además de los significados, el proceso de construcción de estos (Krause, 2007). Para tal efecto, los métodos cualitativos permiten acceder de manera efectiva a la cosmovisión y los estilos de vida de las personas que provienen de una población cultural y lingüística específica (Ponterotto, 2013; Roe \& Lachman, 2005).

El estudio de la experiencia de la depresión desde esta perspectiva abre una línea de exploración que permite ir más allá de la descripción del diagnóstico, para acceder a la construcción de los significados que las personas otorgan a su experiencia. De acuerdo con el Interaccionismo Simbólico, los significados se construyen en la interacción social y constituyen, entonces, un sistema de significados intersubjetivos (Blumer, 1969).

Esta aproximación permite superar las limitaciones planteadas a las miradas estrictamente descriptivas y/o biologicistas de los trastornos mentales, basadas en métodos cuantitativos y en nosologías como las del Diagnostic and Statistical Manual of Mental Disorders (DSM-5), que no consideran en profundidad el aspecto subjetivo de la experiencia de la enfermedad y su imbricación con el contexto social (Roe \& Lachman, 2005). Este tipo de enfoques conllevan una simplificación riesgosa, puesto que reducen la experiencia subjetiva del malestar a una suma de criterios sintomáticos, que no necesariamente captan el modo como estos son vividos por quienes los padecen.

Desde la perspectiva de las Teorías Subjetivas (Groeben, Wahl, Schlee, \& Scheele, 1988), las experiencias de vida tienen diversos tipos de anclaje. El biológico, que viene dado por la provisión de un sistema cognitivo con la disposición para el intercambio social. El social, dado que en las prácticas culturales se produce la construcción del conocimiento. Y el representacional, que tiene simultáneamente un carácter individual y colectivo (Rodrigo, Rodríguez, \& Marrero, 1993). De esta manera, aunque cada persona tiene una situación biográfica específica, los significados tienen un carácter intersubjetivo y cultural (Catalán, 2010), y la recuperación personal ante la enfermedad (Mascayano \& Montenegro, 2017) involucra el reconocimiento de los significados que cada persona atribuye a ella, dentro del contexto más amplio de su vida (Roe \& Lachman, 2005).

Teniendo en cuenta lo anterior, el estudio del proceso de construcción subjetiva de la experiencia de la depresión es inseparable de la consideración de los elementos sociales inherentes. En esta línea, Kleinman (1980; 1995) distingue entre el sufrimiento concebido como la esencia experiencial de la enfermedad y las condiciones sociales de ese sufrimiento, dado que esta no responde a una subjetividad aislada, es el producto de la participación intersubjetiva entre las características morales del entorno social y los procesos políticos macrosociales. El desarrollo y el inicio de los procesos de la enfermedad están determinados por el compromiso activo de la persona en un entorno social particular (Jenkins, 1997; Kleinman, 1980).

Por consiguiente, la experiencia de la depresión trae consigo cambios en el modo como las personas se perciben a sí mismas y a su entorno e incluye su contexto familiar y social. Este proceso, aparentemente individual, se vale de elementos simbólicos 
Pág 145

Según Blaxter (1978), el diagnóstico como categoría está relacionado con la etiqueta que ha sido acordada entre los profesionales médicos para nombrar una condición particular que es considerada patológica. Por otro lado, el diagnóstico como proceso, tiene que ver con las diversas formas en las que se aplica dicha etiqueta. y/o valoraciones contextuales, asociadas al bienestar, la felicidad, la productividad u otras ideas sobre el ser humano en sociedad. En este sentido, la depresión no se agota en sus aspectos biológicos o psicológicos, también está determinada por los significados presentes en el seno de una sociedad (Kleinman \& Good, 1985).

La presencia de sintomatología y malestar puede tener como consecuencia que no se logre hacer una desconexión del yo con la enfermedad y se llegue incluso a la pérdida o reconfiguración de la identidad (Fabrega \& Manning, 1972). Dicha reconfiguración puede darse a través de dos caminos: en el primero, la persona realiza esfuerzos por vivir "separada" de la enfermedad; esta y los síntomas se comprenden como algo ajeno, y la esperanza de la recuperación se limita a la mejora de los síntomas, en lugar de ser integrados al yo. Esta situación se denomina "alienación de los síntomas", y cuando estos son controlados la persona siente que recupera su identidad (Radden, 2008). En el segundo camino, los síntomas son integrados a través de narrativas que, al ocupar un rol central en la formación de la identidad, pueden permitir que la persona se reconozca a sí misma en ellas (Clark, 2008) a través del establecimiento de relaciones causa-efecto, que han sucedido en el contexto de la depresión. Desde esta perspectiva, los síntomas no son únicamente controlados o eliminados, sino que incluso pueden ser valorados y resignificados como parte de la experiencia de vida y la propia identidad. Dependiendo de cuál sea el camino, alienación o integración, los objetivos y expectativas de recuperación podrían ser distintos (Radden, 2008).

Uno de los aspectos que influye en este proceso de reconfiguración es el diagnóstico de depresión. Los diagnósticos se suelen realizar sobre la base de patrones y combinaciones de síntomas que son reportados por los pacientes, los cuales pueden variar de acuerdo con la causa o interpretación dada por el propio paciente (Kokanovic, Bendelow, \& Philip, 2013). Según Blaxter (1978), el diagnóstico como categoría está relacionado con la etiqueta que ha sido acordada entre los profesionales médicos para nombrar una condición particular que es considerada patológica. Por otro lado, el diagnóstico como proceso, tiene que ver con las diversas formas en las que se aplica dicha etiqueta. Esta distinción se observa claramente en el diagnóstico de depresión, ya que en la mayoría de los casos para los pacientes esta experiencia es subjetiva y está ligada estrechamente a circunstancias personales, en tanto que, para los profesionales de la salud, diagnosticar es una acción moderada por las preferencias del terapeuta respecto a tratamiento y distribución de los recursos para dicho tratamiento (Rogers, May, \& Oliver, 2001).

En cuanto a la relación entre diagnóstico y subjetividad, Gara, Rosemberg y Cohen (1987) señalan que las personas con diagnósticos de enfermedad mental pueden experimentar que su yo es absorbido y su identidad secuestrada por el diagnóstico; en parte, por el estigma asociado al mismo. En esta línea, en un estudio realizado en Inglaterra con pacientes con diversos diagnósticos de enfermedad mental, Dinos, Stevens, Serfaty, Weich Y King, (2004) encontraron que el estigma se podía experimentar como un sentimiento subjetivo, asociado a altos niveles de ansiedad, sobre cómo manejar la información relativa a la enfermedad (por ejemplo, si revelarla o no a amigos, familiares y posibles empleadores), en contextos con o sin discriminación manifiesta. No obstante, algunos participantes reportaron efectos positivos al recibir el diagnóstico, tales como aceptación o alivio, principalmente en personas con depresión y/o ansiedad; lo que conducía a una actitud positiva hacia el tratamiento. Así, la experiencia subjetiva frente a los diagnósticos puede favorecer la adherencia al tratamiento (Goerg, Fisher, Zbinden, \& Guimón, 2004). 
Pág 146

El objetivo del presente estudio es comprender las dinámicas mediante las cuales los pacientes significan su experiencia de la depresión.
Existe una incipiente línea de estudios enfocados a examinar la experiencia subjetiva de pacientes con diagnósticos de trastornos mentales según el contexto cultural de los afectados. Así, en un estudio realizado en una población de personas latinas y euroamericanas con diagnósticos de esquizofrenia y depresión en Estados Unidos, Jenkins (1997) encontró que la categoría de enfermedad física era más utilizada por los pacientes euroamericanos, mientras que los pacientes latinos optan por la de enfermedad nerviosa. Asimismo, observó que los individuos intentaban de manera estratégica representarse a sí mismos y a los demás, para evitar quedar marcados por el estigma del trastorno mental.

Considerando lo anterior, el objetivo del presente estudio es comprender las dinámicas mediante las cuales los pacientes significan su experiencia de la depresión.

\section{Metodología}

El presente estudio utilizó un diseño de investigación cualitativo basado en los procesos de análisis de la Teoría Fundamentada (Grounded Theory) (Corbin \& Strauss, 2008). Esta escuela metodológica incorpora elementos interpretativos y se arraiga en el interaccionismo simbólico (Blumer, 1969), que posibilita el estudio de los procesos subjetivos a través de los cuales los individuos interpretan y significan su experiencia de vida. El proceso de análisis contiene una etapa descriptiva que permite la generación de un sistema jerárquico de categorías de análisis, y una analítico-relacional (Krause, 1995), para luego integrar los hallazgos en la elaboración de un modelo conceptual que expone la dinámica mediante la cual las personas entrevistadas construyen significados asociados a su experiencia de la depresión.

\section{Participantes}

El estudio contó con 10 participantes, de ambos géneros ( $80 \%$ femenino), con una edad promedio de 37 años, quienes habían sido atendidos en consulta privada o centros de atención en salud mental. Los datos sociodemográficos y clínicos se presentan con mayor detalle en la Tabla 1. Los criterios de inclusión fueron: (1) haber recibido en algún momento de su vida un diagnóstico de trastorno del ánimo con episodio depresivo, según el criterio clínico del psicólogo/a o psiquiatra tratante; (2) estar o haber estado en tratamiento psicoterapéutico por dicho trastorno. Y los criterios de exclusión fueron: (1) presentar dificultad cognitiva de comprensión y expresión verbal que impida la realización de la entrevista; y, (2) haber recibido diagnóstico de demencia o psicosis. Cabe mencionar que, si bien algunos de los criterios mencionados permiten concluir que existe heterogeneidad en la muestra a partir de las características sociodemográficas o la duración de los tratamientos, esta apertura fue intencional, en tanto se pretendió potenciar la variabilidad en las perspectivas de los participantes, siguiendo lo planteado por Kleining (2007) con respecto a la variación máxima en las muestras como estrategia para acercarse a la pluralidad de las experiencias. 
Tabla 1. Descripción de la muestra

\begin{tabular}{|c|c|c|c|c|c|c|c|c|c|}
\hline ID & $\begin{array}{c}\text { Sistema } \\
\text { asistencial }\end{array}$ & Género & Edad & $\begin{array}{c}\text { Estado } \\
\text { Civil }\end{array}$ & $\begin{array}{c}\text { Nivel } \\
\text { educacional }\end{array}$ & Diagnóstico & $\begin{array}{c}\text { Presencia } \\
\text { Comorbilidad }\end{array}$ & $\begin{array}{c}\text { Tratamiento } \\
\text { Farmacológico }\end{array}$ & $\begin{array}{l}N^{\circ} \text { sesiones } \\
\text { de terapia }\end{array}$ \\
\hline ECO 1 & CSM & M & 40 & Soltero & $\begin{array}{c}\text { Universitario } \\
\text { incompleto }\end{array}$ & $\begin{array}{l}\text { Trastorno depresivo } \\
\text { recurrente moderado }\end{array}$ & $\mathrm{Si}$ & $\mathrm{Si}$ & 36 \\
\hline ECO 2 & CSM & $\mathrm{F}$ & 24 & Casada & Universitario & $\begin{array}{c}\text { Trastorno mixto de } \\
\text { depresión y ansiedad }\end{array}$ & Si & Si & 5 \\
\hline ECO 3 & CSM & $\mathrm{F}$ & 60 & Casada & Universitario & $\begin{array}{c}\text { Trastorno mixto de } \\
\text { depresión y ansiedad }\end{array}$ & Si & No & 15 \\
\hline $\mathrm{ECO} 4$ & CSM & $\mathrm{F}$ & 43 & Soltera & $\begin{array}{c}\text { Técnico- } \\
\text { profesional }\end{array}$ & $\begin{array}{c}\text { Trastorno depresivo } \\
\text { moderado }\end{array}$ & $\mathrm{Si}$ & No & 9 \\
\hline ECO 5 & $\mathrm{CP}$ & $\mathrm{F}$ & 22 & Soltera & Universitario & $\begin{array}{c}\text { Trastorno depresivo } \\
\text { moderado }\end{array}$ & $\mathrm{Si}$ & $\mathrm{Si}$ & 36 \\
\hline ECL 1 & $\mathrm{CP}$ & $\mathrm{F}$ & 44 & Casada & $\begin{array}{c}\text { Técnico- } \\
\text { profesional }\end{array}$ & $\begin{array}{c}\text { Trastorno bipolar } \\
\text { tipo II }\end{array}$ & $\mathrm{Si}$ & $\mathrm{Si}$ & $\geq 100$ \\
\hline ECL 2 & $\mathrm{CP}$ & $\mathrm{F}$ & 38 & Soltera & Universitario & $\begin{array}{c}\text { Trastorno depresivo } \\
\text { moderado }\end{array}$ & $\mathrm{Si}$ & $\mathrm{Si}$ & $s / i$ \\
\hline ECL 9 & CSM & $\mathrm{F}$ & 44 & Soltera & Universitario & $\begin{array}{c}\text { Trastorno depresivo } \\
\text { severo }\end{array}$ & $\mathrm{Si}$ & $\mathrm{Si}$ & $\geq 30$ \\
\hline ECL 10 & $\mathrm{CP}$ & $\mathrm{F}$ & 33 & Casada & $\begin{array}{l}\text { Técnico- } \\
\text { profesional }\end{array}$ & $\begin{array}{c}\text { Trastorno depresivo } \\
\text { moderado }\end{array}$ & $\mathrm{Si}$ & $\mathrm{Si}$ & $s / i$ \\
\hline ECL 11 & CUSM & M & 23 & Soltero & $\begin{array}{c}\text { Estudiante } \\
\text { universitario }\end{array}$ & $\begin{array}{c}\text { Trastorno depresivo } \\
\text { severo }\end{array}$ & No & si & $\geq 50$ \\
\hline
\end{tabular}

CSM = Centro de Salud Mental; $\mathrm{CP}=$ Consultorio Privado; $\mathrm{CUSM}=$ Centro Universitario de Salud Mental; $\mathrm{ECL}=$ Entrevistado chileno; $\mathrm{ECO}=$ Entrevistado colombiano

\section{Recolección de información}

La información se recolectó a través de entrevistas semiestructuradas con cada participante, realizada de forma presencial, con una duración de 60 a 90 minutos; las cuales fueron grabadas en audio y luego transcritas para su análisis. Si bien se desarrolló un guion con las preguntas y temas que debían ser abordados, el orden en que eran presentados por los entrevistadores se adaptó al relato de cada participante. Se les permitió contar su experiencia en la secuencia que les pareciese más adecuada, y se les motivó a desarrollar sus respuestas de manera espontánea y reflexiva (Flick, 2014; Kvale, 2011).

Cada entrevista se inició con la pregunta: "Cuénteme cómo ha sido para usted la experiencia de tener depresión. Quiero recoger, en primer lugar, sus impresiones más espontáneas sobre su experiencia, lo que se le venga a la mente", para luego profundizar en cada núcleo temático: (1) Contexto de la depresión (cuál era el contexto previo a la depresión, cómo era la experiencia de vida de los entrevistados cuando se sentían saludables o estables); (2) Cambios o acontecimientos que posiblemente llevaron a los participantes a la depresión, o que comenzaron a notar al sentirse deprimidos (cambios en lo familiar, lo laboral, en las amistades, en lo amoroso, entre otros); (3) Experiencia personal con el trastorno (cómo se manifestaron los síntomas depresivos, cómo vivían los entrevistados/as un buen/mal día, cómo lograban calmarse/relajarse o manejar los síntomas); (4) Ayuda recibida (cómo, cuándo y qué tipo de ayuda buscaron); (5) La experiencia del proceso de recuperación (cuáles fueron los signos de cambio/mejoría y cómo vivieron aquel proceso).

Dado que los participantes eran de dos países diferentes (Colombia y Chile), los guiones fueron piloteados en cada país, para luego de las dos primeras entrevistas ser ajustados según las diferencias idiomáticas. 
Pág 148

Los objetos del análisis fueron, por un lado, la experiencia de la depresión relatada por los participantes y, por otro, las dinámicas a través de las cuales significaban esta experiencia como "depresiva" o bajo el rótulo de "depresión".

\section{Procedimiento de muestreo}

Se estableció contacto con centros de salud mental y psicólogos de consultas privadas especializados en el trabajo con pacientes con diagnóstico de depresión. Estos pacientes fueron contactados e invitados a participar por un integrante del equipo de investigación, que les explicó en qué consistía su participación en el estudio y les informó sobre la confidencialidad con relación a los datos recolectados. Quienes consintieron participar de manera voluntaria, acordaron con el investigador el lugar y hora de la entrevista (centro de atención al que asisten o sus propias casas). Los entrevistadores eran psicólogos clínicos con experiencia en atención de pacientes o estudiantes de pregrado en psicología, entrenados/as previamente en la técnica de la entrevista, ajenos a los centros de salud, al participante y a los terapeutas tratantes.

\section{Análisis de datos}

El proceso de análisis se realizó siguiendo los procedimientos de categorización descriptiva y relacional de la Teoría Fundamentada (Grounded Theory) (Corbin \& Straus, 2008). Inicialmente, se realizó una lectura analítica de las transcripciones siguiendo los núcleos temáticos de la entrevista, para luego dar paso a la codificación abierta descriptiva, en la cual el texto fue dividido en unidades de significado (códigos) que se etiquetaron con el lenguaje utilizado por los participantes, para luego integrarlas gradualmente en grupos mayores según sus temáticas y frecuencia (Ponterotto, 2013). Posteriormente, se llevó a cabo una codificación relacional, en la cual se identificaron conexiones e interacciones entre las categorías y se extrajo una lógica central que las integrara (Glaser \& Strauss, 1967). Para garantizar confiabilidad y validez en el análisis de datos, cada entrevista fue analizada por cuatro grupos de codificadores conformados por los miembros del equipo de investigación (psicólogos entrenados en Teoría Fundamentada), quienes llevaron a cabo un proceso de acuerdo intersubjetivo sobre los códigos y las relaciones observadas entre ellos, para luego desarrollar colectivamente conceptos que permitieran dar cuenta de los fenómenos que emergieron del análisis (Galeano, 2004).

Los objetos del análisis fueron, por un lado, la experiencia de la depresión relatada por los participantes y, por otro, las dinámicas a través de las cuales significaban esta experiencia como "depresiva" o bajo el rótulo de "depresión".

\section{Consideraciones éticas}

El presente estudio forma parte del proyecto "La experiencia de la depresión: una perspectiva internacional", a cargo del Instituto Milenio para la investigación en Depresión y Personalidad (MIDAP). Durante su ejecución, se siguieron todos los protocolos éticos exigidos para este tipo de investigaciones. A su vez, se contó con la aprobación ética de la Escuela de Psicología de la Universidad Diego Portales (Chile), de la Universidad CES (Colombia) y de la Human Science Division, Faculty of Core Research, Ochanomizu University (Japan), ya que los datos recogidos forman parte de un proyecto internacional.

Los participantes firmaron un consentimiento informado previo a la realización de la entrevista, en el que se les comunicaba respecto del uso que se daría al material recolectado y la confidencialidad con la que se manejarían los datos. Los participantes que estuviesen en tratamiento al momento de la entrevista requirieron aprobación de su terapeuta para poder participar, en favor de cuidar que la entrevista no fuese una instancia que pudiese afectar significativamente su estado de ánimo. 


\section{Resultados}

El fenómeno central a partir del cual se estructuran los resultados es la "Construcción subjetiva de la experiencia de la depresión", que recoge la manera como los entrevistados representan "lo depresivo", desde su origen hasta la actualidad. En función de esto, se construyó un esquema (ver Figura 1) que da cuenta de la manera cómo este fenómeno evoluciona en el tiempo, en términos de acontecimientos asociados y experiencias relatadas por los participantes. En este proceso de construcción subjetiva se destacaron tres fenómenos secundarios: (1) La experiencia de un malestar sin nombre; (2) El anclaje de la experiencia en la palabra "depresión"; y (3) La apropiación de la experiencia de la depresión.

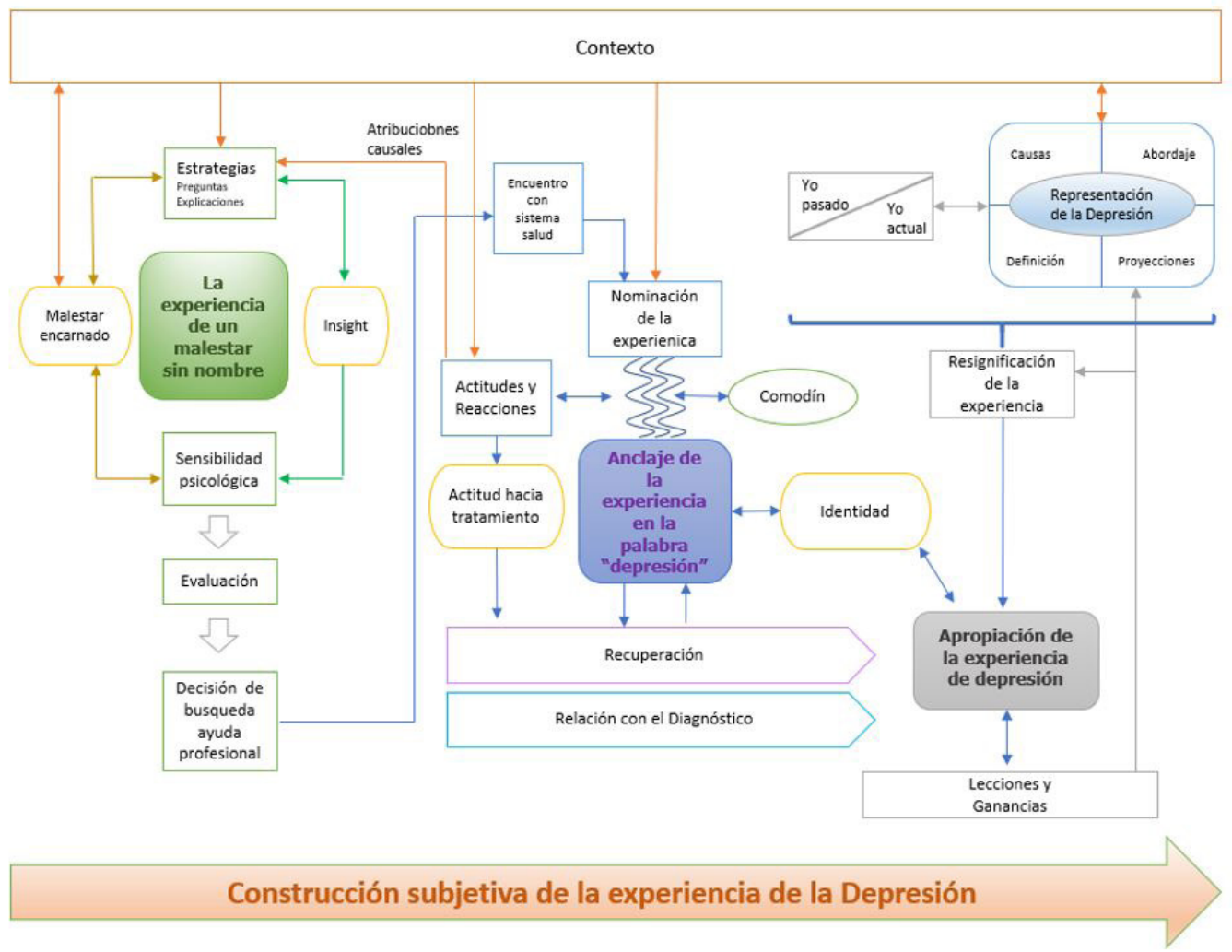

Figura 1. Esquema relacional de la Construcción subjetiva de la experiencia de la Depresión, construido a partir de los resultados de las entrevistas

El primer fenómeno que se observa, "La experiencia de un malestar sin nombre", se refiere a cómo los entrevistados, previo a reconocerse "deprimidos", se encontraban en un estado de desconocimiento, extrañeza y preocupación, respecto de múltiples malestares que les acontecían. Notar cambios en la personalidad, sentirse diferente a los demás, aislarse, sentir falta de ánimo y pérdida de interés, llorar, presentar dolores somáticos, problemas en el sueño, tristeza e ideas de muerte, fueron algunas de las primeras señales que mostraron que "algo andaba mal", y que se debía hacer algo al respecto. En este primer momento, el malestar aparece como una serie de fragmentos desarticulados, sin representación alguna que los encauce, localizado como algo que ocurre en el cuerpo o el comportamiento, y que agota las maneras de referirlos en el sentimiento mismo que lo encarna; por lo cual esta situación se denominó "Malestar encarnado". Algunos participantes interpretaron su malestar como consecuencia de estresores contextuales contingentes (problemas en las relaciones 
interpersonales, problemas socioeconómicos, entre otros) y, también, como la causa de problemáticas en su entorno (término de relaciones de pareja, problemas familiares y problemas en el trabajo). Así lo expresa una de las participantes:

Empecé a sentirme extraña, o sea yo sabía que algo me estaba pasando y que no estaba actuando normal, en el sentido de que estaba muy desganada. Yo tiendo a ser solitaria por personalidad, pero había llegado a un extremo de que prácticamente me estaba aislando, ¿ya? entonces empecé a notar que me venía algo, algo no estaba bien en mí (ECL9: 2).

Como se muestra en la Figura 2., estos malestares fueron las primeras señales de que "Algo andaba mal", dando paso a diversas estrategias orientadas a abordar esta problemática. Principalmente, los esfuerzos de los participantes se dirigieron a resolver preguntas del tipo "¿Qué me está pasando?", “¿Estoy enfermo?" o “¿Esto es normal?" y las respuestas procedieron de múltiples fuentes de información: experiencias personales, anécdotas del entorno cercano, opiniones de familiares, amigos y conocidos. A partir de lo anterior, obtuvieron recomendaciones ("pensar en cosas positivas te mejora", "debes hacer algo al respecto"), elaboraron teorías ("esto es estrés", "esto es normal", "esto es depresión") e incluso recibieron críticas ("está llamando la atención", "exagera", "débil de cabeza"). Aquí el contexto participa como fuente de información y, también, como activador que impulsa a las personas participantes a alarmarse y buscar ayuda.

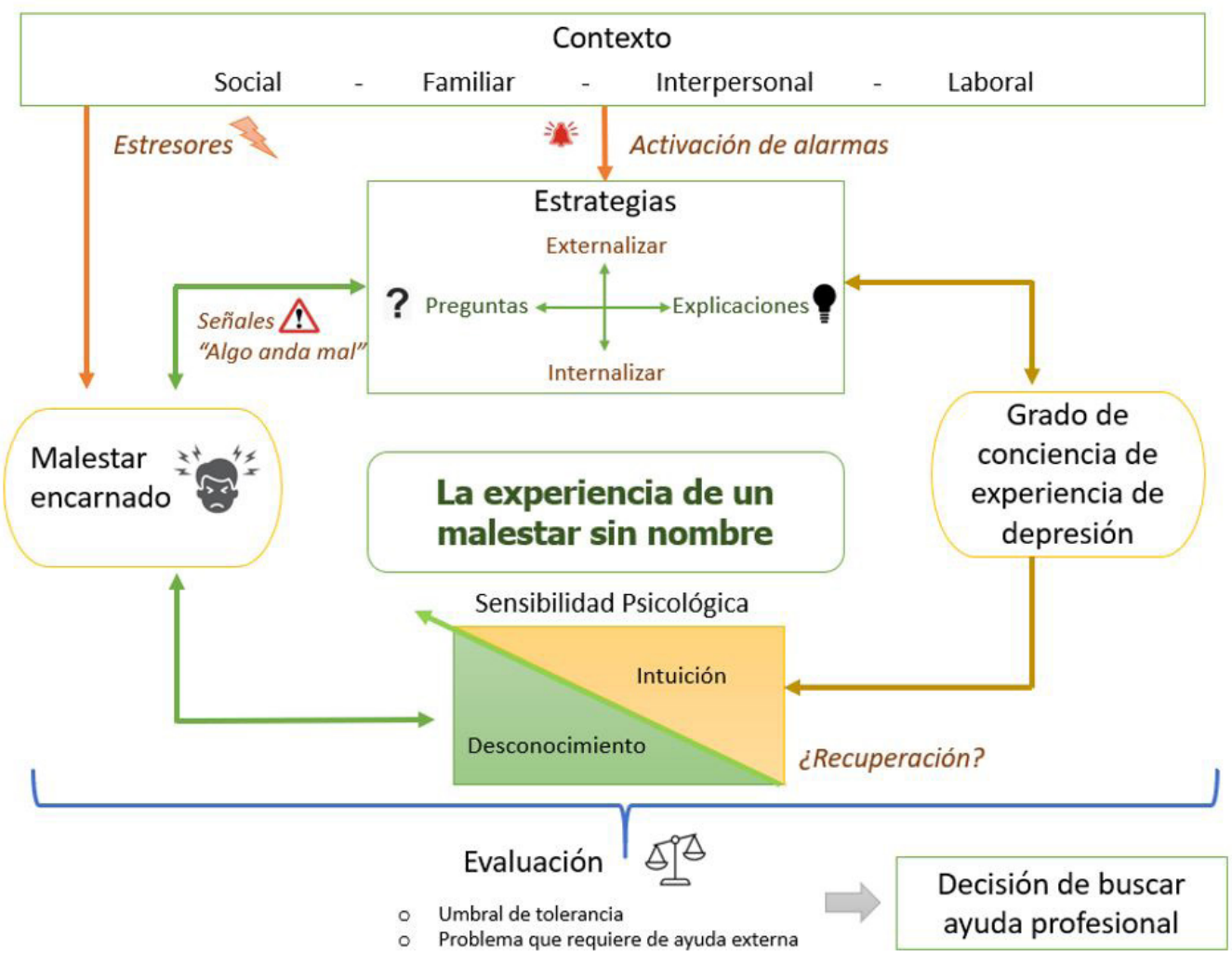

Figura 2. Esquema relacional del fenómeno "La experiencia de un malestar sin nombre" 
En función de los relatos, se pudo notar que varios de ellos intuían que estaban pasando por una depresión, mientras que otros todavía se sentían desorientados respecto de lo que les ocurría.
La comprensión del malestar inicial que construyeron los participantes se debatió entre dos extremos: (1) una lógica externalizadora, en la que el malestar es entendido como algo ajeno, extraño, y que se resolverá sin injerencia alguna o por intervención de un tercero; (2) una lógica internalizadora, en la que la persona se siente identificada y responsable de lo que le está ocurriendo; que puede llegar a normalizar el malestar por reconocerlo como parte de ser quien es. Dice una de las personas entrevistadas:

(...) yo había comprendido que eso se había convertido en algo muy normal de mi vida - ehh - que no es tan normal, para el resto del mundo. Entonces ella me decía esas cosas (...) que yo vengo de una depresión más o menos hace 10 años sin darme cuenta (EC01:14).

A su vez, esta situación generó distintos grados de conciencia respecto a la valoración o comprensión de su experiencia como "depresión", lo que se denominó "Sensibilidad psicológica". En función de los relatos, se pudo notar que varios de ellos intuían que estaban pasando por una depresión, mientras que otros todavía se sentían desorientados respecto de lo que les ocurría.

Luego de abordar las preguntas, recibir opiniones, construir explicaciones, y desarrollar diferentes grados de sensibilidad psicológica, los participantes evaluaban su malestar en función de si era tolerable o si era necesaria ayuda externa. En los casos en que parecía ser un problema con el que se puede cargar por sí solo, se repetía el ciclo hasta ahora expuesto; de lo contrario, buscaban ayuda profesional. Así lo expone una de ellas: "(...) yo apenas pasé con este tema de que sentí ganas de matarme y todo, yo dije de inmediato en mi casa que yo iba a buscar ayuda médica porque necesitaba ayuda (...)" (ECL9:44).

En el encuentro con un profesional de la salud (psiquiatra, psicólogo, neurólogo, ginecólogo, entre otros), aparece la nominación de la experiencia del paciente como "depresión" o "depresiva". Si bien no es la primera vez que surge esta etiqueta (puesto que, podría haber sido planteada por familiares, conocidos o intuido por el propio entrevistado), sí es la primera vez que alguien con experiencia y autoridad, a quien se le atribuye un saber respecto de la salud y la enfermedad, introduce la palabra "depresión" como una respuesta a las preguntas de los participantes, como un diagnóstico, como un calificativo de la cualidad de su experiencia y como un paso hacia el proceso de recuperación. Al respecto dice una de ellas:

(...) yo no lo había identificado y, ahí, cuando fui al psiquiatra, cuando le empecé a contar lo que me pasaba y en varias sesiones, se dio cuenta que yo desde hace muchos años había tenido como episodios, pero salía sola a flote, varias veces me pasó (ECL2:3,4).

Como consecuencia de lo anterior, se inaugura el proceso de construcción de un nuevo fenómeno: el "Anclaje de la experiencia del paciente en la palabra depresión"; esto es, que la palabra "depresión" cumplirá el rol de reunir y sujetar las experiencias de malestar que hasta el momento se encontraban fragmentadas y dispersas; lo que permitirá significarlas como partes de un mismo constructo $y$, también, resignificar experiencias previas en función de esta nueva mirada. Ahora bien, para la mayoría de los entrevistados, la trayectoria recorrida para llegar a tal punto no fue fácil y depende del procesamiento que se realice de dos factores principales: (1) 
las actitudes y reacciones propiciadas por el encuentro con la palabra "depresión"; y (2) el uso de la palabra "depresión" de manera flexible, a modo de "comodín" (ver Figura 3).

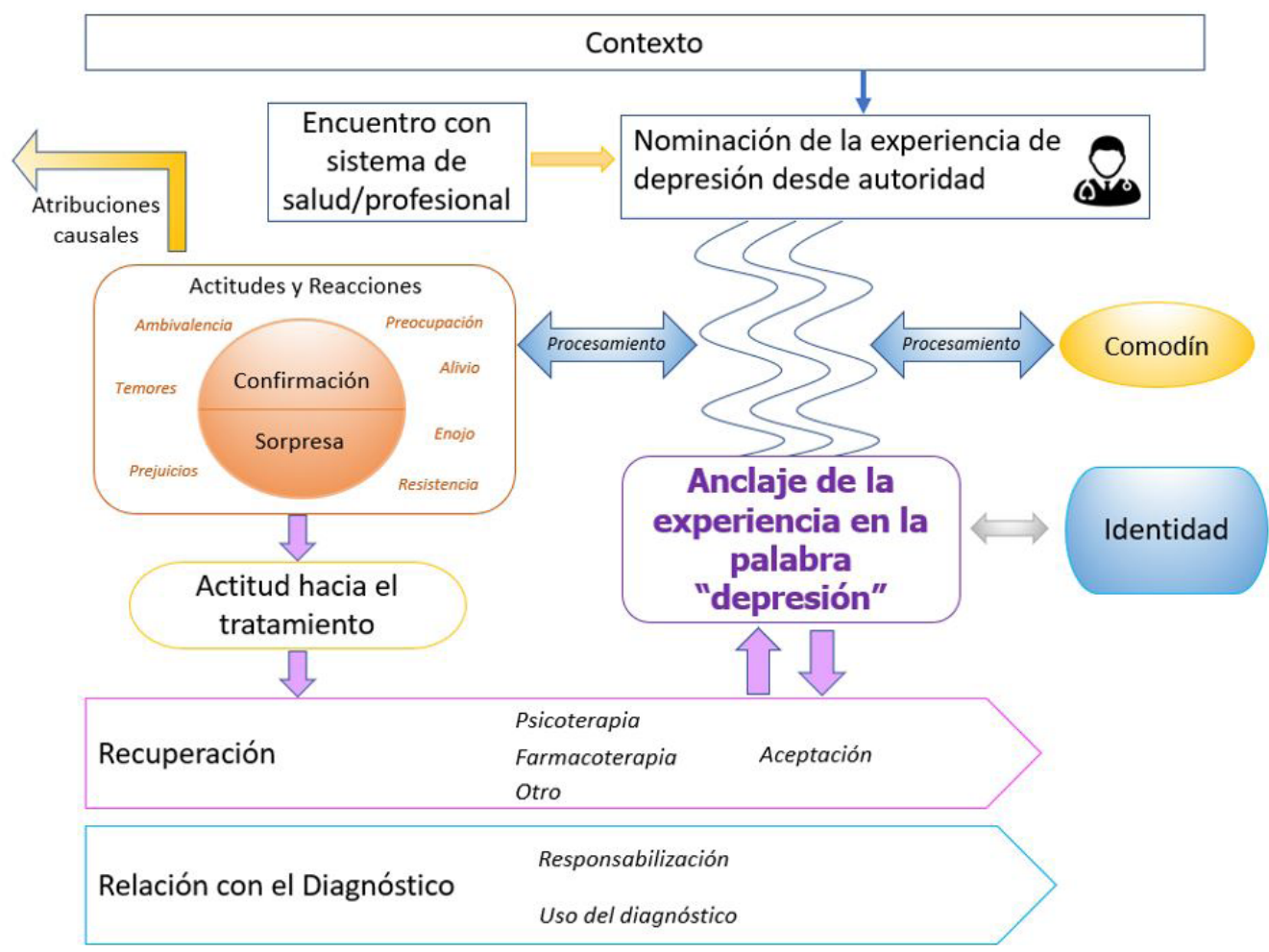

Figura 3. Esquema relacional del fenómeno "Anclaje de la experiencia en la palabra depresión"

La introducción de la palabra "depresión" en esta fase del proceso de construcción de significado de la experiencia de la depresión provoca múltiples impresiones, que provienen no solo de la propia individualidad sino también del contexto. Para los participantes con baja sensibilidad psicológica, desorientados y extrañados respecto de lo que les ocurría, el término "depresión" aparecía de manera sorpresiva, activaba preocupaciones, prejuicios, estigmas y temores respecto de la enfermedad mental o la depresión e incitaba preguntas como: “¿Durará para siempre?", “¿Esto quiere decir que me voy a suicidar?", “Esto quiere decir que estoy loco?". En los casos contrarios, quienes presentaron alta sensibilidad psicológica e intuían que padecían depresión, el hecho de que un profesional de la salud así lo consignara, se experimentaba como una confirmación de lo esperado e, incluso, se recibía con indiferencia.

Cabe agregar que estas actitudes y reacciones también se trasladan al tratamiento y la recuperación; tal como se observa en el siguiente testimonio:

Entonces dije voy donde un neurólogo a que me dé un remedio para la concentración, porque no me estoy concentrando (...) [neurólogo] 'ah ya, como que vienes con el diagnóstico listo, te voy a hacer unas pocas preguntas primero y según eso yo te doy un remedio, si es lo que necesitas o si no, no'. Pasaron 5 minutos y yo me puse a llorar, así de mal, y él me dijo 'mira en verdad lo que tú necesitas, el problema que tú tienes no es de concentración, estás mal 
Cuando se hace referencia a que la palabra "depresión" cumple el rol de "comodín", se rescata el hecho de que los entrevistados hacen uso singular del término, que no necesariamente coincide con el rótulo psiquiátrico de "depresión". anímicamente' (...) Salí enojadísima, con más ganas de llorar... y qué se cree, cómo me manda ahora más encima a otro doctor y a un psiquiatra, si no estoy loca (...) (ECL2:2).

Cuando se hace referencia a que la palabra "depresión" cumple el rol de "comodín", se rescata el hecho de que los entrevistados hacen uso singular del término, que no necesariamente coincide con el rótulo psiquiátrico de "depresión". Durante las entrevistas los participantes refirieron múltiples hechos y experiencias que claramente caracterizan un cuadro depresivo, pero también usaron la palabra "depresión" para referirse a sucesos que bien podrían ser crisis de pánico, rasgos de un trastorno de personalidad, problemas neurológico-funcionales o experiencias no catalogables dentro de la nosología psiquiátrica. En suma, que los participantes pudiesen hacer de la palabra "depresión" una herramienta flexible, que sirviese a la necesidad de dar cabida en el habla a un malestar que se encontraba carente de representación, fue un aspecto influyente en la trayectoria hacia el anclaje.

Todo lo anterior es abordado y elaborado por el paciente, tanto de manera personal como interpersonal en el espacio terapéutico, familiar, de pareja, laboral, entre otros, y es denominado en el esquema relacional del fenómeno "Anclaje de la experiencia en la palabra depresión" como "procesamiento" (ver Figura 3).

Cuando los participantes se involucran en la experiencia de asistir a un tratamiento surgen expectativas y esperanzas de recuperación, que comprometen una dimensión relevante y novedosa. La recuperación es visualizada por los sujetos como un proceso largo y lento, que no se produce de forma espontánea, sino que requiere de ayuda especializada, apoyada en medicamentos y psicoterapia, además de un gran aporte personal, familiar, de amigos y del entorno laboral; y significa volver a lograr un nivel de funcionamiento adaptativo y saludable, pero no una recuperación total, dado que consideran que se mantienen ciertos aspectos "depresivos" que ahora son parte de la persona. Para los participantes, la recuperación es más bien darse cuenta de ciertas características o vulnerabilidades y desarrollar las habilidades para enfrentar momentos/eventos difíciles; en ese sentido, puede haber recaídas. Así lo describe una de las personas entrevistadas: “(..) pues me imagino que esto cura no tendrá, pero al menos sí cómo aprender uno a manejarlo, o a controlarlo. Entonces por esa parte también me animé mucho" (EC04:60).

La recuperación de los entrevistados se presentó en distintos ámbitos de la vida. Se apreció disminución de los síntomas físicos (mayor energía, calidad del sueño, mejora en el ánimo, disminución de la angustia y activación conductual); en al ámbito psicológico se percibió menor autoexigencia y mayor aceptación de sí mismo, motivación, conocimiento, diferenciación y autorregulación de las emociones, lo que generó sensación de empoderamiento. También implicó resignificar eventos vitales, tomar nuevas perspectivas de sí mismo y los otros, así como una mayor capacidad de reflexión e introspección. En el ámbito interpersonal mejoró la calidad de los vínculos con familiares y amigos y se logró mayor conexión emocional y cercanía con ellos. Al respecto una de las personas entrevistadas dice: "Entendí muchas cosas, muchas cosas de todo, cómo había sido toda la vida y por qué me habían pasado todas esas cosas" (ECL2: 177).

Por otro lado, durante el tratamiento los participantes elaboraron la representación de la depresión como un diagnóstico que se puede aceptar de manera progresiva, rechazando los estigmas asociados, lo cual se aprecia en esta respuesta: "Acepté la 
Pág 154

La aparición del diagnóstico de depresión puede conllevar una demanda de responsabilización por lo ocurrido, tanto del entorno, como de ellos mismos. depresión; fue súper importante porque cuando uno acepta como que libera entonces no tenía la presión como de que 'pues ¡Estás triste!'” (ECO2: 12).

A lo anterior se agrega que la aparición del diagnóstico de depresión puede conllevar una demanda de responsabilización por lo ocurrido, tanto del entorno, como de ellos mismos; tal como lo expresa una de las personas entrevistadas:

O sea, yo tengo una depresión y la depresión no es culpa de nadie, ni del psicólogo, ni del psiquiatra, ni del perro, ni del gato, ni de mi mamá, ni de mi esposo, ni de nadie. Es culpa de uno mismo, porque uno fue el que dejó que pasaran las barreras que uno mismo tiene como ser humano, que se las atravesaran, que lo pisotearan si lo están pisoteando, que lo denigraran si lo están denigrando. Pues, porque pueden pasar muchas cosas, que precisamente eso es lo que a uno lo lleva a una depresión; porque lo hacen sentir tan mal, que uno ya no se siente útil. ¿Pero quién permitió eso? Uno. ¿Entonces quién es el que se tiene que fortalecer? Uno, que no puede permitir que eso vuelva a pasar (EC05: 42).

Finalmente, el fenómeno de anclaje trae consecuencias significativas sobre la identidad de los sujetos, que comienzan desde el momento en que se denomina "depresión" a su experiencia. De aquí en adelante, los espacios y circunstancias en las cuales se haga referencia a la "depresión" o a lo "depresivo", se tornan interpelantes en un sentido íntimo. Lo que los participantes entienden que su entorno comprende por "depresión", ahora les acontece como un significado asociado a ellos. Recordar anécdotas de terceros e historias personales en las que se presenció o fantaseó respecto de la depresión o la enfermedad mental, ahora conlleva un vínculo que no existía anteriormente. Y desarrollan una manera de abordar las interacciones sociales, que considera esta nueva ramificación de su identidad como una persona "depresiva", "deprimida" o con "depresión". Al respecto, una de las personas entrevistadas afirma:

(...) siempre traté que nadie supiera que yo tenía depresión, porque veía que si alguien me trataba como que yo tenía depresión, era como 'jah! pobrecito', como un bicho raro algo así, entonces de cierta forma nunca asumí que tuviera, nunca les dije a los demás que tenía depresión (ECL11: 231).

El proceso identitario asociado al "anclaje" de la experiencia con la palabra "depresión", acompañado por el trabajo de aceptación característico del proceso de recuperación, dan paso al tercer y último fenómeno que permite dar cuenta del proceso de construcción subjetiva de la depresión, la "Apropiación de la experiencia de la depresión". En este momento los participantes se expresan respecto de su experiencia de "depresión", e incluso la "depresión" en general, como algo sobre lo cual pueden hablar con propiedad y ofrecer algunos consejos; también desarrollan una mirada crítica sobre las maneras en que ellos, ellas y su entorno significaban anteriormente la depresión. Al respecto dice una de las personas entrevistadas:

Claro, es que yo creo que es la ignorancia de las personas también, en que la depresión no es cómo lo mismo que tener no sé ... esas personas que se vuelven locas y explotan y quieren destruir todo el mundo. Yo creo que la gente lo ve como si fuera algo de ese estilo (ECL11: 235). 
En este punto la mayoría de las personas entrevistadas fueron capaces de reconocer lecciones y ganancias que la depresión trajo a su vida. Entre ellas se destacó la importancia de buscar ayuda, pero también el reconocerse a sí mismos como el principal agente de cambio, mantener la esperanza de recuperarse, estar alerta a la depresión en otros, pensar que la depresión tiene un sentido o razón de ser y considerar que ahora poseen un mayor conocimiento de sí mismos, según se deriva del siguiente testimonio:

Lo más importante es reconocer que uno está enfermo, porque parece que acá, acá como que en Chile en general siento yo, tener una enfermedad mental como... no sé, como que tuvieras un cartel de..." jah! eres un inútil", es una enfermedad, no es nada más que eso, entonces intentar de reconocerse enfermo y buscar ayuda (ECL9: 158).

Lo anterior, dio cuenta de dos interacciones: (1) los participantes se sienten con capacidad de hablar con propiedad sobre el tema, y ofrecer guías o consejos respecto de cómo entender y abordar la depresión; (2) han construido nuevas maneras de representarse la depresión, son capaces de definirla, interpretar sus causas, proponer abordajes y proyectarse hacia un futuro que considera la depresión como posibilidad (ver Figura 4).

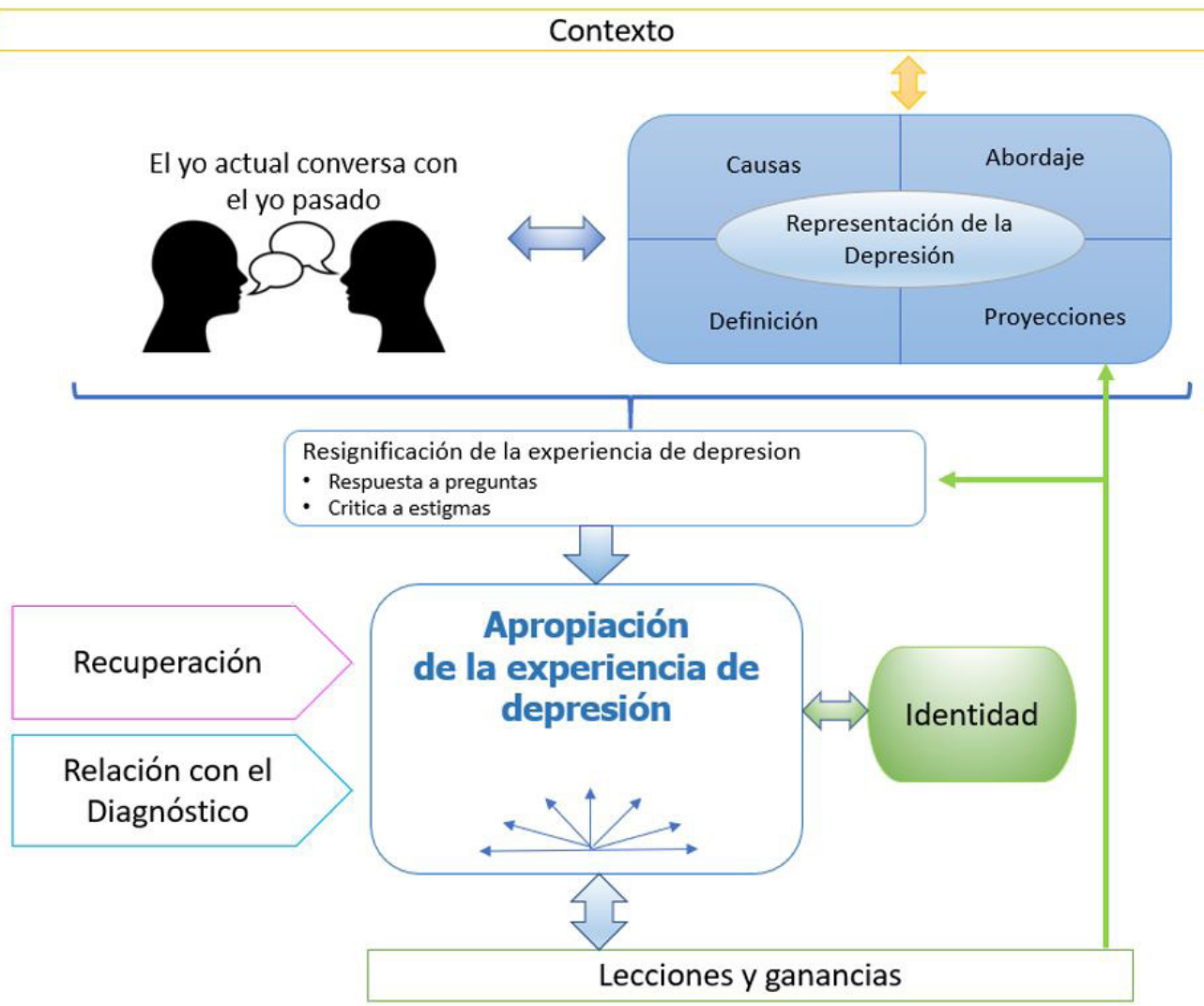

Figura 4. Esquema relacional del fenómeno "Apropiación de la experiencia de la depresión" 
Pág 156

El proceso de construcción del significado personal de la experiencia de la depresión se caracterizó por tres fenómenos que se suceden uno a otro: (1) La experiencia de un malestar sin nombre; (2) El anclaje de la experiencia en la palabra depresión; (3) La apropiación de la experiencia de la depresión.
Esta nueva mirada implica un diálogo entre los sujetos y su contexto, entre su "yo actual" y su "yo pasado", en el que cuestionan o legitiman las opiniones que han recibido. Se rememoran los acontecimientos y experiencias que se suscitaron durante este trayecto, y que hoy son observados con una mirada distinta, capaz de reconocer depresión donde antes había normalidad; capaz de representarse un entendimiento en el que el malestar aparentemente extraño y sin razón de ser, tiene un sentido; capaz de criticarse constructivamente y señalar momentos y personas que obraron a favor o en contra de su proceso de recuperación; capaz de cuestionar, criticar y deslindarse de prejuicios y estigmatizaciones. En suma, resignificar las experiencias pasadas para construir un significado propio de la experiencia de la depresión en su vida. Al respecto, dice una de las personas entrevistadas:

Lo que pasa es que, en ese momento, uno no tiene claro que eso pasa y que después de cada tempestad de esas es un nuevo aprendizaje y una mejor vida que uno vive. 0 sea, después de cada depresión, la vida vuelve y renace y la vida vuelve y toma sentido, y cada vez uno es más útil para el mundo. Yo siempre he pensado eso, yo cada que veo mis depresiones, siempre han tenido un objetivo y siempre ha sido en mejoramiento de calidad de vida para mí y para los que están al lado mío. Lo que pasa es que eso a uno nadie se lo dice (ECO5: 10).

\section{Discusión}

El proceso de construcción del significado personal de la experiencia de la depresión se caracterizó por tres fenómenos que se suceden uno a otro: (1) La experiencia de un malestar sin nombre; (2) El anclaje de la experiencia en la palabra depresión; (3) La apropiación de la experiencia de la depresión.

En el primero, los participantes experimentan el malestar como algo desconcertante, extraño y preocupante, al que no se pueden atribuir causas, ni tampoco soluciones, pero que por el sufrimiento que implica y las consecuencias que tiene sobre su entorno, moviliza a buscar respuestas y explicaciones en sus amigos, familiares y en su propia historia de vida. Según lo que surja de esta búsqueda, desarrollan distintos grados de "sensibilidad psicológica", es decir, de intuición respecto a nombrar como "depresión" el malestar que experimentan. Si ese malestar es insoportable, buscan ayuda con algún profesional de la salud, quien, desde una posición de conocimiento y experiencia, lo denomina como "depresión". En este punto se inaugura la trayectoria hacia el segundo fenómeno, momento en que la experiencia previa se comienza a anclar en la palabra "depresión", permitiendo representar lo que era experimentado como un malestar ambiguo y fragmentado, integrándose a un acervo previo de sentido y facilitando su comunicación (Jovchelovitch, 2007; Krause, 2011).

Así, la denominación "depresión" provoca un proceso de elaboración de actitudes y reacciones, lo que involucra el uso flexible que se hace de esta palabra (a modo de "comodín") y aborda las preocupaciones, los prejuicios y los temores asociados a la depresión. Esto se ve influenciado por el proceso de recuperación, en el que se experimenta la depresión no solo como malestar, sino como algo de lo cual se puede mejorar.

A su vez, esto trae consecuencias importantes sobre la identidad, ya que el anclaje de la experiencia lleva a que los sujetos se consideren parte de aquello a lo que la palabra "depresión" refiere, comiencen a cuestionarse cómo abordar este nuevo constructo, que ahora los interpela personalmente, en relación con su entorno y consigo mismos. 
Los resultados de la presente investigación concuerdan con lo propuesto por Krause (2011), quien señala que la decisión de buscar ayuda profesional ocurre cuando la persona se ve confrontada con sus propios límites, producto del crecimiento del malestar (p. ej. el aumento de los síntomas y su intensidad y la interferencia de estos con diferentes ámbitos de la vida).
Lo anterior da paso al tercer fenómeno, en el cual los sujetos utilizan la noción de "depresión" como algo que forma parte de su vida y de lo cual pueden hablar con propiedad; esto se refleja en su capacidad para construir nociones sobre cómo abordarla, qué la causa y caracteriza, llegando a cuestionar y resignificar el sentido que ellos y su entorno le otorgaban a esta palabra en otros momentos de su historia.

De acuerdo con los resultados descritos, al principio surge una experiencia sin nombre, en la cual hay una identificación de señales, sensaciones corporales, cambios conductuales y emocionales, que se perciben de manera desarticulada, como una sensación de malestar generalizado o como eventos cotidianos que son parte del día a día. Esto coincide con lo referido por Martínez-Hernáez y García (2010), quienes encontraron que las personas con depresión tienden a nombrar su malestar como estrés, rabia, apatía, tristeza o preocupación. Estas primeras señales, pueden ser interpretadas como algo externo, que así como apareció de pronto también puede desaparecer, o bien ser solucionado por un tercero; llegando a ser "normalizadas", atribuidas a la personalidad, como algo que siempre ha estado allí. Este hallazgo coincide con otros estudios que muestran la asimilación de los síntomas típicos de la depresión al devenir de problemas de la vida cotidiana (Riveros, Bohórquez, Gómez-Restrepo, \& Okuda, 2006).

Del mismo modo, las personas que rodean a quien padece depresión suelen atribuir estas señales o conductas a aspectos reprochables de su personalidad y las relacionan con pereza, ociosidad, irritabilidad o debilidad mental; ofreciendo explicaciones y recomendaciones al respecto. Esto corresponde a lo encontrado por Pezo, Costa, y Komura (2004), quienes señalan que la identificación y comprensión de estas conductas como síntomas de una enfermedad, por parte del contexto social, laboral y familiar, bien no se daba o era un proceso demorado, por considerar que siempre han estado presentes, son reflejo de pereza o son cambios aislados.

Para las personas con depresión, la relación con los síntomas evoluciona. La persistencia e intensidad del malestar hace que lentamente se identifique que "algo está mal", que "eso no es normal". Este paso no necesariamente va de la mano con la intuición de que los síntomas físicos o emocionales se corresponden con algún diagnóstico, razón por la cual, en ocasiones, la búsqueda de ayuda es evitada o aplazada, dado que, como plantean también otros estudios (Martínez-Hernáez \& García, 2010; Pezo et al., 2004; Riveros et al., 2006), hay desconocimiento o preconceptos estigmatizantes respecto a la enfermedad mental. En este punto, los contextos socioeconómicos y culturales juegan un papel importante en la manera como se vive subjetivamente ese momento inicial de la experiencia, lo que repercute en la comprensión de los síntomas "depresivos" y en la búsqueda de ayuda (Gómez et al., 2012; Kim, 2008; Krause, 2011).

Los resultados de la presente investigación concuerdan con lo propuesto por Krause (2011), quien señala que la decisión de buscar ayuda profesional ocurre cuando la persona se ve confrontada con sus propios límites, producto del crecimiento del malestar (p. ej. el aumento de los síntomas y su intensidad y la interferencia de estos con diferentes ámbitos de la vida). En ese sentido, la búsqueda de ayuda profesional se da, en algunos casos, cuando la persona ya ha hecho intentos personales para sentirse mejor, ha recurrido a sus redes de apoyo familiar o social o cuando alguien sugiere buscar ayuda. Una vez se da el contacto con un profesional de la salud, al cual se atribuye conocimiento y experiencia, se consolida la denominación de su malestar bajo la palabra "depresión". Este encuentro permite que el conglomerado de sensaciones asociadas al malestar sea abarcado por el diagnóstico, lo que esclarece esta 
Pág 158

De acuerdo con los participantes del presente estudio nominar la experiencia bajo el rótulo de "depresión", o calificarla de "depresiva", tenía efectos sobre la recuperación. Además, consideran que el trabajo terapéutico va mucho más allá de la disminución o desaparición de los síntomas, puesto que implica cambios en la percepción de sí, de otros y en el modo de relacionarse. experiencia y promueve el camino a la comprensión de lo que les sucede (Gómez et al., 2012). Al respecto, Kokanovic, Bendelow y Philip (2013) señalan que otorgar un nombre al malestar puede ser visto como uno de los primeros pasos de un proceso más largo y difícil en el que las personas intentan sentirse mejor; y cómo, en dicho proceso, aparecen reflexiones acerca de etapas anteriores de la vida (infancia o juventud), que permiten interpretar los acontecimientos anteriores como signos de lo que vendría luego.

De acuerdo con los participantes del presente estudio nominar la experiencia bajo el rótulo de "depresión", o calificarla de "depresiva", tenía efectos sobre la recuperación. Además, consideran que el trabajo terapéutico va mucho más allá de la disminución o desaparición de los síntomas, puesto que implica cambios en la percepción de sí, de otros y en el modo de relacionarse. Lo anterior se vincula con lo descrito por Radden (2008), respecto a que la recuperación de la depresión se facilita cuando esta es integrada más allá de lo sintomático; lo que conlleva una reconstrucción de la identidad, en la que el trastorno se sitúa como una experiencia en la vida de los sujetos, con causas, consecuencias y, en algunos casos, aprendizajes posteriores, lo que permite otorgar nuevos significados y valoraciones acerca del malestar sentido. Esta integración implica una apropiación a partir de la cual las personas pueden convivir con la depresión, en una especie de sano equilibrio, que solo es posible si se acepta su existencia,y se elige de manera responsable cuidarse y responder a sus señales.

Finalmente, a partir de la profundización en la experiencia de la depresión de los participantes, se observa que el diagnóstico formal dado desde la nosología del DSM no logra capturar una parte importante del malestar. El hecho de que utilicen la palabra depresión como un comodín, es decir, como algo que permite referir el malestar que no necesariamente coincide con los criterios formales asociados a esta psicopatología, muestra la insuficiencia de dichos criterios para captar la subjetividad del paciente. En el relato de las personas entrevistadas, se observa que la riqueza de la denominación diagnóstica depende de su adaptación al malestar subjetivo de quien se encuentra sufriendo, lo cual confirma la noción de que la recuperación personal involucra el reconocimiento de los significados que cada persona atribuye a su enfermedad, dentro del contexto más amplio que implica su propia vida (Mascayano \& Montenegro, 2017; Roe, \& Lachman, 2005).

\section{Implicaciones para la práctica clínica}

Los resultados de este estudio tienen implicaciones relevantes para la práctica clínica, en particular, respecto del uso que se hace de los diagnósticos en el proceso terapéutico; en el cual es fundamental considerar al menos tres reflexiones: (1) El diagnóstico tendrá un impacto en el paciente y en su entorno, y activará preguntas, preocupaciones y posibles estigmas, que pueden tener consecuencias en su malestar y en el tratamiento; (2) El diagnóstico se ofrece como una herramienta de trabajo que permite construir un punto de apertura hacia el malestar del paciente; (3) El profesional de la salud debe tomar en consideración el momento o fase en la que se encuentra el paciente en términos de la relación con su experiencia de malestar, ya que esto permitirá una comprensión más atingente respecto del modo en que esta se manifiesta en el individuo y, por tanto, hacia dónde podría dirigir el tratamiento. 


\section{Limitaciones y recomendaciones}

Si bien las personas participantes hacen alusión al aporte y a la interacción con sus terapeutas, los hallazgos de este estudio se hubieran beneficiado con la mirada de dichos actores con el fin de construir el fenómeno de forma interactiva e intersubjetiva.

La dificultad de reclutar participantes constituye una limitación para estudios con esta metodología, puesto que tiene repercusiones en la homogeneidad de la muestra, y de ahí en la variabilidad o profundidad de los datos y resultados.

Para futuras investigaciones se recomienda profundizar en la relación entre la experiencia del malestar y la denominación del mismo, a través de otros diagnósticos (inclusive fuera del campo de la salud mental), u otras referencias semánticas, para así fortalecer los tratamientos y enriquecer una mirada de la salud que reconozca el lugar que ocupa la subjetividad de los pacientes en su proceso de recuperación.

\section{Agradecimientos}

Este trabajo fue financiado por ANID - Iniciativa Científica Milenio / Instituto Milenio para la Investigación en Depresión y Personalidad-MIDAP ICS13_005.

\section{Referencias}

Berger, T., \& Luckman, P. (1968). La construcción social de la realidad. Buenos Aires: Amorrortu.

Blaxter, M. (1978). Diagnosis as category and process: The case of alcoholism. Social Science \& Medicine. Medical Psychology and Medical Sociology, 12, 9-17. https:// doi.org/10.1016/0271-7123(78)90017-2

Blumer, H. (1969). Symbolic Interaction: Perspective and Method. Englewood Cliffs N.J: Prentice Hall.

Botto, A., Acuña, J., \& Jiménez, J. P. (2014). La depresión como un diagnóstico complejo. Implicancias para el desarrollo de recomendaciones clínicas. Revista Médica de Chile, 142, 1297-1305. https://doi.org/10.4067/s0034-98872014001000010

Catalán, J. (2010). Teorías Subjetivas: Aspectos teóricos y prácticos. La Serena: Universidad de la Serena.

Clark, H. (2008). Depression and Narrative: Telling the Dark. Albany, New York: University of New York Press.

Centro de Estudios de Conflicto y Cohesión Social (COES). (2018). Resultados Primera Ola, Estudio Longitudinal Social de Chile (ELSOC). Módulo 6: Salud y bienestar. Salud Mental en el Chile de hoy. Notas COES de Política Pública N¹5. Santiago, Chile: COES. Recuperado de https://coes.cl/wp-content/uploads/2018/01/N6.ELSOC.-Salud-y-bienestar.pdf

Corbin, J., \& Strauss, A. (2008). Strategies for qualitative data analysis. Basics of Qualitative Research. Techniques and procedures for developing grounded theory. (3rd ed.). San José, California: SAGE.

Corveleyn, J., Luyten, P., \& Blatt, S.J. (2005). The theory and treatment of depression: Towards a dynamic interactionism model. Leuven, Belgium: Leuven University Press.

Subsecretaría de Salud Pública. (2017). Encuesta nacional de salud 2016-2017 Primeros resultados. Santiago. https://www.minsal.cl/wp-content/uploads/2017/11/ ENS-2016-17 PRIMEROS-RESULTADOS.pdf

Dinos, S., Stevens, S, Serfaty, M., Weich, S., \& King, M. (2004). Stigma: the feelings and experiences of 46 people with mental illness. British Journal of Psychiatry, 184(2), 176-181. https://doi.org/10.1192/bjp.184.2.176 
Fabrega, H., \& Manning, P. K. (1972). Disease, illness and deviant careers. Theoretical perspectives on deviance. New York: Basic Books.

Flick, U. (2014). Mapping the field. The SAGE handbook of qualitative data analysis. Los Angeles, CA: SAGE.

Galeano, M. E. (2004). Diseño de proyectos en la investigación cualitativa. Medellín: Universidad EAFIT.

Gara, M.A., Rosenberg, S., \& Cohen, B. (1987). Personal identity and the schizophrenic process: An integration. Psychiatry, 50(3), 267-279. https://doi.org/10.1080/003 32747.1987.11024358

Glaser, B., \& Strauss, A. (1967). The discovery of grounded theory. Chicago: Aldine Press.

Goerg, D., Fischer, W., Zbinden, E., \& Guimón, J. (2004). Diferenciación en las representaciones sociales de los trastornos mentales y los tratamientos psiquiátricos. European Journal of Psychiatry, 18(4), 225-234. https://doi.org/10.4321/s1579$\underline{699 \times 2004000400004}$

Gómez, C. C., Balsategui, A. R., Gordon, J. P., De La Hera, A. B., Atxutegi, E. Z., \& Metcalfe, I. M. (2012). Perspectivas de los pacientes diagnosticados de depresión y atendidos por médicos de familia y psiquiatras. Atención primaria, 44(10), 595602. https://doi.org/10.1016/j.aprim.2012.02.009

Groeben, N., Wahl, D., Schlee, J., \& Scheele, B. (1988). Das Forschungsprogramm Subjektive Theorien. Tübingen: Francke.

Holtzheimer, P. E., \& Mayberg, H. S. (2011). Stuck in a rut: Rethinking depression and its treatment. Trends in neurosciences, 34(1), 1-9. https://doi.org/10.1016/j. tins.2010.10.004

Jenkins, J. H. (1997). Subjective experience of persistent schizophrenia and depression among US Latinos and Euro-Americans. The British Journal of Psychiatry, 171, 20-25. https://doi.org/10.1192/bjp.171.1.20

Jovchelovitch, S. (2007). Knowledge in context: Representations, community, and culture. London New York, NY: Routledge.

Kvale, S. (2011). Las entrevistas en investigación cualitativa. Madrid: Ediciones Morata.

Kim, D. (2008). Blues from the neighborhood? Neighborhood characteristics and depression. Epidemiologic reviews, 30(1), 101-117. https://doi.org/10.1093/epirev/ mxn009

Kleining, G. (2007). Der qualitative Forschungsprozess. En G. Naderer, \& E. Balzer (Eds.), Qualitative Marktforschung in Theorie und Praxis: Grundlagen, Methoden und Praxis (pp. 189-230). Wiesbaden: Gabler. https://nbn-resolving.org/ urn:nbn:de:0168-ssoar-8931

Kokanovic, R., Bendelow, G., \& Philip, B. (2013). Depression: the ambivalence of diagnosis. Sociology of health \& illness, 35(3), 377-390. https://doi.org/10.1111/ j.1467-9566.2012.01486.x

Krause, M. (1995). La investigación cualitativa: Un campo de posibilidades y desafíos. Revista Temas de Educación, 7, 19-39.

Krause, M. (2007). La psicoterapia al microscopio. Gaceta de Psiquiatría Universitaria, 3(3), 258-265.

Krause, M. (2011). Psicoterapia y Cambio. Una mirada desde la subjetividad (2da ed.). Santiago de Chile: Ediciones Universidad Católica.

Krause, M., Güell, P., Jaramillo, A., Zilveti, M., Jiménez, J. P., \& Luyten, P. (2015). Changing communities and increases in the prevalence of depression: is there a relationship? Universitas Psychologica, 14(4), 1259-1268. https://doi. org/10.11144/javeriana.upsy14-4.ccip 
Kleinman, A. (1980). Patients and Healers in the Context of Culture. An Exploration of the Borderland between Anthropology, Medicine, and Psychiatry. Berkeley, CA: University of California Press.

Kleinman A., \& Good B. (1985). Culture and depression: Studies in the Anthropology and Cross- Cultural Psychiatry of Affect and Disorder. Los Angeles: University of California Press.

Kleinman, A. (1995). Writing at the Margin: Discourse between Anthropology and Medicine. Berkeley, CA: University of California Press.

Luyten, P., Blatt, S., \& Corveleyn. (2005). The theory and treatment of depression. Towards a dynamic interactionism model. Leuven: Leuven University Press.

Martínez-Hernáez, Á., \& García, A. M. (2010). «Un infinito que no acaba». Modelos explicativos sobre la depresión y el malestar emocional entre los adolescentes barceloneses (España). Primera parte. Salud mental, 33(2), 145-152.

Ministerio de Salud y Protección Social y Colciencias. (2015). Encuesta Nacional de Salud Mental 2015, tomo I. Bogotá. http://www.odc.gov.co/Portals/1/publicaciones/pdf/consumo/estudios/nacionales/C0031102015-salud mental tomol. pdf

Mascayano, F., \& Montenegro, C. R. (2017). El 'modelo de la recuperación' y la reforma de la atención en salud mental. VERTEX, Revista Argentina de Psiquiatría, XXVIII, 460-467.

Organización Mundial de la Salud. (2020). Depresión. https://www.who.int/es/newsroom/fact-sheets/detail/depression

Pezo Silva, M. C., Costa Stefanelli, M., \& Komura Hoga, L. A. (2004). La familia conviviendo con la depresión: de la incomprensión inicial a la búsqueda de ayuda. Index de Enfermería, 13(47), 11-15. https://doi.org/10.4321/s1132-12962004000300003

Ponterotto, J. (2013). Qualitative Research in Multicultural Psychology: Philosophical Underpinnings, Popular Approaches, and Ethical Considerations. Qualitative Psychology, 1(S), 19-32. https://doi.org/10.1037/2326-3598.1.s.19

Radden, J. (2008). My Symptoms, Myself: Reading Mental Illness Memoirs for Identity Assumptions. In Clark, H. Depression and Narrative: Telling the Dark. Albany, N.Y.: University of New York Press.

Riveros Vargas, M., Bohórquez Peñaranda, A., Gómez-Restrepo, C., \& Okuda Benavides, M. (2006). Conocimientos sobre la depresión en pacientes que asisten a centros de atención primaria en Bogotá, Colombia. Resultados colombianos del Proyecto Internacional de Depresión. Revista Colombiana de Psiquiatría, 25(1), Recuperado de: https://www.redalyc.org/pdf/806/80635102.pdf

Rodrigo, M. J., Rodríguez, A., \& Marrero, J. (1993). Las teorías implícitas: Una aproximación al conocimiento cotidiano. Madrid: Visor Distribuciones S.A.

Rogers, A., May, C., \& Oliver, D. (2001). Experiencing depression, experiencing the depressed: the separate worlds of patients and doctors. Journal of Mental Health, 10(3), 317-333. https://doi.org/10.1080/09638230125545

Roe, D., \& Lachman, M. (2005). The subjective experience of people with severe mental illness: A potentially crucial piece of the puzzle. Israel Journal of Psychiatry and Related Science, 42(4), 223-230.

Sobocki, P., Jönsson B., Angst J., \& Rehnberg C. (2006). Cost of depression in Europe. Journal of Mental Health Policy and Economics 9(2), 87-98.

Villaseñor, S. J., Rojas, C., Albarrán, A. J., \& Gonzáles, A. G. (2006). Un enfoque transcultural de la depresión. Revista de Neuropsiquiatría, 69(1-4), 43-50. https://doi. org/10.20453/rnp.v69i1-4.1600 